\title{
Erratum to: 3D $\pi$-Conjugated Poly(amic) Acid Polymer as Support Matrices for Ethanol Electro-Oxidation on Palladium and Platinum Catalysts
}

\author{
Victor M. Kariuki ${ }^{1}$ - Jing Zhang ${ }^{1}$ - Magdalena Parlinska-Wojtan ${ }^{2}$. \\ Omowunmi A. Sadik ${ }^{1}$
}

Published online: 17 May 2016

(C) Springer Science+Business Media New York 2016

Erratum to: Electrocatalysis

DOI 10.1007/s12678-016-0307-0

There was an error in the name of the third author. The correct name is Magdalena Parlinska-Wojtan. Also, her affiliation should be changed to Institute of Nuclear Physics Polish Academy of Sciences, PL-31342 Krakow, Poland.

The online version of the original article can be found at $\mathrm{http}: / \mathrm{dx}$.doi.org/ 10.1007/s12678-016-0307-0.

\section{$\triangle$ Omowunmi A. Sadik \\ OSADIK@BINGHAMTON.EDU}

1 Department of Chemistry, Center for Advanced Sensors and Environmental Systems (CASE), State University of New York at Binghamton, P.O Box 6000, Binghamton, NY 13902, USA

2 Institute of Nuclear Physics, Polish Academy of Sciences, PL-31342, Krakow, Poland 